\title{
An improved method for analyzing chlormequat and mepiquat in source waters by solid-phase extraction and liquid chromatography-mass spectrometry
}

\author{
Zhiyong $\mathrm{Yu}^{\mathrm{a}}$, Fen Jin ${ }^{\mathrm{b}}$, Jianying $\mathrm{Hu}^{\mathrm{c}}{ }$, Xi Zhang ${ }^{\mathrm{b}}$, Jingfang Sun ${ }^{\mathrm{a}}$, Min Yang ${ }^{\mathrm{a}, *}$ \\ a State Key Laboratory of Environmental Aquatic Chemistry, Research Center for Eco-Environmental Sciences, \\ Chinese Academy of Sciences, 18 Shuangqing Road, Haidian District, Beijing 100085, China \\ ${ }^{\mathrm{b}}$ Key Laboratory of Agro-product Quality and Safety, Institute of Quality Standards E Testing Technology for Agri-products, \\ Chinese Academy of Agricultural Sciences, Beijing 100081, China \\ c College of Urban and Environmental Sciences, Peking University, Yiheyuan 5\#, Beijing 100871, China
}

\section{A R T I C L E I N F O}

\section{Article history:}

Received 30 April 2010

Received in revised form 24 July 2010

Accepted 9 August 2010

Available online 17 August 2010

\section{Keywords:}

Liquid chromatography-mass spectrometry

Plant growth regulator

Source water

Chlormequat

Mepiquat

\begin{abstract}
A B S T R A C T
A liquid chromatography-mass spectrometry (LC-MS) method for the identification and quantification of chlormequat (CQ) and mepiquat (MQ) in source waters with high sensitivity and specificity was established using WCX cartridges $(150 \mathrm{mg} / 6 \mathrm{~mL})$ for pre-concentration of the samples and using the CAPCELL PAK CR 1:4 $(2.0 \mathrm{~mm} \times 150 \mathrm{~mm} 5 \mu \mathrm{m}$, SCX:C18 =1:4) column containing strong cationic exchange resins and $\mathrm{C} 18$ for separation. The method could solve the problem for pre-concentrating ionic compounds from water samples and avoid the MS instrument fouling problem accompanied with the use of ion-pair reagents. After the optimization of analytical conditions, quantification was achieved in the positive electrospray ionization mode using selected ion monitoring. The samples were analyzed with multi-channel mode with quantification performed at $30 \mathrm{~V}$ cone voltage to ascertain the sensitivity and qualitative analysis performed at $60 \mathrm{~V}$ cone voltage simultaneously. The method detection limits (MDLs) of CQ and MQ in source water were determined to be 14 and $22 \mathrm{ng} \mathrm{L}^{-1}$. Finally, the method was used to quantify CQ and $\mathrm{MQ}$ in several source waters, which gave a level ranging from below the quantitation limit to $28 \mathrm{ng} \mathrm{L}^{-1}$.
\end{abstract}

(c) 2010 Elsevier B.V. All rights reserved.

\section{Introduction}

The occurrence of plant growth regulators in the environment has gained attention worldwide in recent years due to their widespread application [1-4]. Chlormequat (CQ) and mepiquat (MQ), the two quaternary ammonium compounds, are widely applied as the plant growth regulators to promote flower formation, improve fruit setting in fruits and vegetables and reduce vegetative growth and the inhibition of sprouting [2,5,6]. CQ also elicits adverse effects on animal reproduction and has been classified as a suspected endocrine disruptor in the database of toxic chemical substances (RTECS) by the National Institute for Occupational Safety and Health (NIOSH) [7]. CQ and MQ have been classified in the Pesticide Residues Monitoring List (PRML) produced by the European Union (EU), which specifies $0.1 \mu \mathrm{gL}^{-1}$ as the limit for individual pesticides and $0.5 \mu \mathrm{g} \mathrm{L}^{-1}$ for total pesticides $[1,2,8]$.

HPLC coupled to mass spectrometry (LC-MS) or tandem MS (LC-MS-MS) has been used to analyze plant growth regulators in water $[1,2,4,6,9,10]$. Pre-concentration is required to meet the

\footnotetext{
* Corresponding author. Tel.: +86 10 62923475; fax: +861062923475.

E-mail address: yangmin@rcees.ac.cn (M. Yang).
}

requirement of the PRML for analysis of environmental samples, which is difficult because CQ and MQ are ionic compounds and with high water solubility [8]. Vidal et al. used HLB cartridges for the pre-concentration of CQ and MQ from environmental samples in conjunction with ion-pair reagents [11]. However, HLB cartridges are generally not considered to be suitable for the preconcentration of polar compounds [12]. In addition, the use of ion-pair reagents for pre-concentration makes the SPE procedure complicated. It has been shown that Weak Cation-eXchange (WCX) cartridge is suitable for the pre-concentration of paraquat and diquat, which also belongs to the quaternary ammonium family, from river water samples without the addition of ion-pair reagents $[13,14]$.

In addition, it is also important to solve the separation problem for the successful analysis of CQ and MQ using HPLC. Ion-pair reagents such as heptafluorobutyric acid (HFBA) have been used to improve the retention and separation of CQ and MQ on C18 column $[8,11]$. The use of ion-pair reagents, however, could easily contaminate the mass spectrometer, resulting in the need for frequent cleaning [15-17]. Hydrophilic interaction liquid chromatography (HILIC) column has been recently used to solve the separation problem [18]. However, related studies are minimal, and further studies are required to establish a solid method for the routine analysis of these quaternary ammonium pesticides. In principle, 
Table 1

Chemical structures, ion characteristics and optimal cone voltages of CQ and MQ.

\begin{tabular}{|c|c|c|c|c|c|c|}
\hline Plant growth regulators & MW & Structure & Precursor ions $(m / z)$ & Qualifier ions $(m / z)$ & Retention time (min) & Cone voltage $(\mathrm{V})$ \\
\hline Chlormequat (CQ) & 122.6 & $\mathrm{ClCH}_{2} \mathrm{CH}_{2} \mathrm{~N}-\mathrm{CH}_{3}$ & 122 & 58,124 & 9.62 & 30 \\
\hline Mepiquat (MQ) & 114.2 & & 114 & 98,115 & 11.56 & 30 \\
\hline
\end{tabular}

strong cationic exchange resin columns, such as CAPCELL PAK CR column consisting of strong cationic exchange resins and $\mathrm{C} 18$, could provide appropriate separation and retention of the cationic compounds. In this study, an LC-MS method was developed to analyze CQ and MQ in source waters using WCX cartridges $(150 \mathrm{mg} / 6 \mathrm{~mL})$ for pre-concentration of the samples and using a CAPCELL PAK CR $1: 4(2.0 \mathrm{~mm} \times 150 \mathrm{~mm} 5 \mu \mathrm{m}, \mathrm{SCX}: \mathrm{C} 18=1: 4)$ column consisting of strong cationic exchange resins and $\mathrm{C} 18$ to remove the need for the use of ion-pair reagents. The method was then used to analyze source water samples from different regions.

\section{Experimental}

\subsection{Chemicals}

Chlormequat chloride (2-chloroethyltrimethylammonium, CQ, $99 \pm 0.5 \%)$ and mepiquat chloride (1,1'-dimethylpyperidinium, MQ $99 \pm 0.5 \%)$ were purchased from Labor Dr. Ehrenstorfer-Schaefers (Germany). Table 1 shows the chemical structures and molecular weights of CQ and MQ. Acetonitrile and methanol (HPLC grade) were obtained from Fisher Scientific (Houston, TX, USA). Trifluoroacetic acid (TFA, HPLC grade, 99.8\%), acetic acid (HPLC grade, 99.7\%), $\mathrm{CH}_{3} \mathrm{COONH}_{4}$ (99.5\%), and heptafluorobutyric acid (HFBA, HPLC grade, 99.7\%) were obtained from Dima Technology Inc. (USA). Ammonia solution $\left(\mathrm{NH}_{3} \cdot \mathrm{H}_{2} \mathrm{O}\right.$, analysis grade, $\left.25 \%\right)$ and ethylenediaminetetraacetic acid disodium salt $\left(\mathrm{Na}_{2}\right.$ EDTA, analysis grade, 99\%) were purchased form the Beijing Chemical Reagents Company (Beijing, China).

Stock solutions of CQ and MQ were prepared by dissolving each compound in acetonitrile at a concentration of $1000 \mathrm{mg} \mathrm{L}^{-1}$ and then stored at $4{ }^{\circ} \mathrm{C}$ in a refrigerator until use.

\subsection{Sample collection and preparation}

Source water from the Miyun Reservoir in Beijing was free from CQ and MQ and used as a reference matrix for development of the method. The conductivity of the water was around $350 \mu \mathrm{s} \mathrm{cm}^{-1}$. Five other source water samples, including three river water samples (Changjiang, Haihe, Weifang) and two groundwater samples (Huairou1\#, Huairou2\#) were also collected between December 2008 and April 2009 and the residual levels of CQ and MQ in these samples were then analyzed. All samples were filtered through $0.45 \mu \mathrm{m}$ glass fiber filters and stored in PVF bottles at $4{ }^{\circ} \mathrm{C}$ in a refrigerator until analysis. It was confirmed previously that the concentrations of CQ and MQ in source water samples did not change within 15 days at $4{ }^{\circ} \mathrm{C}$. So all of the samples were analyzed within 15 days.

\subsection{Solid-phase extraction}

WCX cartridges were applied to pre-concentrate the selected plant growth regulators. Briefly, $0.06 \mathrm{~g} \mathrm{Na}_{2}$ EDTA was added to $100 \mathrm{~mL}$ water samples, after which the $\mathrm{pH}$ of the samples was adjusted to $9.2-9.3$ with $5 \% \mathrm{NH}_{3} \cdot \mathrm{H}_{2} \mathrm{O}$. Oasis ${ }^{\circledR}$ WCX cartridges (150 mg/6 mL, Waters, Milford, MA) were then sequentially preconditioned with $1 \mathrm{~mL}$ of methanol and $1 \mathrm{~mL}$ of deionized (DI) water. The water samples were then loaded at a flow rate of approximately $1 \mathrm{~mL} \mathrm{~min}^{-1}$, after which the WCX cartridges were washed with $1 \mathrm{~mL}$ methanol. The cartridges were then eluted with $1.5 \mathrm{~mL}$ of an acetonitrile/water/TFA mixture (84:14:2, v/v/v) while being kept wet. Finally, the eluate was dried under a gentle stream of $\mathrm{N}_{2}$ and then redissolved with $0.8 \mathrm{~mL}$ of acetonitrile and $0.2 \mathrm{~mL}$ of DI water for analysis with LC-MS.

Stability tests for CQ and MQ at a pH of 9.2 were conducted under the following experimental conditions: CQ or MQ concentration in DI water, $1 \mu \mathrm{g} \mathrm{L}^{-1}$; $\mathrm{pH}, 9.2$ (using $5 \% \mathrm{NH}_{3} \cdot \mathrm{H}_{2} \mathrm{O}$ ); temperature, $20^{\circ} \mathrm{C}$.

\subsection{LC-MS system}

The compounds were separated on an Alliance 2695 Liquid Chromatograph (Waters, USA) equipped with a CAPCELL PAK CR $1: 4$ column $(2.0 \mathrm{~mm} \times 150 \mathrm{~mm} 5 \mu \mathrm{m}$, SHISEIDO, Japan $)$ using an isocratic method. The composition of the mobile phase was $80 \%$ acetonitrile and $20 \% \mathrm{CH}_{3} \mathrm{COOH}-\mathrm{CH}_{3} \mathrm{COONH}_{4}$ buffer at $20 \mathrm{mM}$, and the flow rate was $0.2 \mathrm{~mL} \mathrm{~min}^{-1}$. The column temperature was $30^{\circ} \mathrm{C}$ and the injection volume was $10 \mu \mathrm{L}$.

The compounds were detected using a single-quadruple mass spectrometer ZQ 4000 (Waters, USA) equipped with an electrospray ionization (ESI) source in positive ion mode. Single standard solutions of CQ and MQ prepared in acetonitrile-pure water (80:20, $\mathrm{v} / \mathrm{v}$ ) were first injected to optimize the MS operation parameters. The optimal conditions for the MS system were determined to be as follows: cove voltage $30 \mathrm{~V}$, capillary voltage $3.0 \mathrm{kV}$, extractor voltage $1 \mathrm{~V}$, Rf lens voltage $0.3 \mathrm{kV}$, source temperature $130^{\circ} \mathrm{C}$, desolvation temperature $350^{\circ} \mathrm{C}$, cone gas flow $50 \mathrm{~L} \mathrm{~h}^{-1}$ and desolvation gas flow $400 \mathrm{~L} \mathrm{~h}^{-1}$. Selected ion monitoring (SIM) mode was chosen for quantification.

\subsection{Method validation}

CQ and MQ were primarily transformed to molecular ions (i.e. $[\mathrm{M}]^{+}$) which were used to quantify the target compounds. The identification of individual plant growth regulators was based on the chromatographic retention time (with $2 \%$ ) and the ratio (within $20 \%$ ) of the three selected characteristic ions. Standard calibration curves and matrix-matched calibration curves were both established for quantification of plant growth regulators in the DI water and the source water, respectively.

All equipment rinses were conducted using methanol to avoid sample contamination, and laboratory blanks were analyzed to assess potential sample contamination. CQ and MQ were spiked at three concentration levels $\left(0.1,0.5\right.$, and $\left.1 \mu \mathrm{g} \mathrm{L}^{-1}\right)$ into DI water and the source water from the Miyun reservoir to calculate the recoveries. Instrument detection limit (IDL) based on an S/N of 10:1 was calculated by injecting $10 \mu \mathrm{L}$ of standard solutions at low concentrations. The method detection limit (MDL) was calculated by 
analyzing seven spiked reference matrix samples at a concentration of $0.1 \mu \mathrm{g} \mathrm{L}^{-1}$ according to the EPA method.

\section{Results and discussion}

\subsection{Optimization of solid-phase extraction}

The effectiveness of extraction using an Oasis ${ }^{\circledR}$ HLB (Hydrophilic-Lipophilic Balance) cartridge was compared with that obtained using an Oasis ${ }^{\circledR}$ WCX (Weak Cation-eXchange) cartridge. HLB cartridges were subjected to the same conditions that were used in a previous study; specifically, an ion-pair reagent ( $100 \mu \mathrm{L}$ HFBA) was added to DI water and the $\mathrm{pH}$ was adjusted to 4.2 using $\mathrm{CH}_{3} \mathrm{COOH}-\mathrm{CH}_{3} \mathrm{COONH}_{4}$ buffer [11]. As a result, the recoveries of $\mathrm{CQ}$ and $\mathrm{MQ}$ were less than $10 \%$ in our experiment, which was reasonable because of the strong polarity of these two compounds. This result, however, was different from the results of the previously conducted study. On the other hand, the recoveries of CQ and MQ in DI water were $97.2 \%$ and $106.4 \%$, respectively, when the WCX cartridges were used. However, the recoveries in the source water samples were very low (15-30\%), suggesting the existence of interference by matrix ions in the source water including $\mathrm{Ca}^{2+}\left(50 \mathrm{mg} \mathrm{L}^{-1}\right)$ and $\mathrm{Mg}^{2+}\left(23 \mathrm{mg} \mathrm{L}^{-1}\right)$. After adding $0.6 \mathrm{~g} \mathrm{~L}^{-1} \mathrm{Na}_{2}$ EDTA to the source water to chelate the above matrix ions, a recovery of greater than $90 \%$ was acquired for CQ and MQ.

In addition, the $\mathrm{pH}$ of water samples was also a critical factor affecting the adsorption capacity of the WCX cartridges for CQ and $\mathrm{MQ}$. The $\mathrm{p} K_{\mathrm{a}}$ of the adsorption material $(\mathrm{RCOOH})$ in the WCX cartridges is approximately 5.5 [12]; therefore, the $\mathrm{pH}$ of the water samples was adjusted to $9.1-9.3$ with $5 \% \mathrm{NH}_{3} \cdot \mathrm{H}_{2} \mathrm{O}$ to realize complete ionization of the acetic groups on the adsorption material. It is well known that MQ undergoes hydrolysis in strongly alkaline solution. Vidal et al. [11] have succeeded in the analysis of MQ by adjusting the sample $\mathrm{pH}$ to 9 with $\mathrm{NaOH}$ before SPE. The stability of CQ and MQ $\left(1 \mu \mathrm{g} \mathrm{L}^{-1}\right)$ under a $\mathrm{pH}$ of 9.2 (using $5 \% \mathrm{NH}_{3} \cdot \mathrm{H}_{2} \mathrm{O}$ ) was further investigated. It was found that CQ was stable for $6 \mathrm{~h}$ and MQ was stable for $3 \mathrm{~h}$ at a $\mathrm{pH}$ of 9.2. The SPE step took approximately $2 \mathrm{~h}$, so hydrolysis of CQ and MQ should not be a problem in this study. Although good recovery for paraquat and diquat were gained when $25 \mathrm{mM}$ buffer with a $\mathrm{pH}=7$ and methanol were used to wash the WCX cartridges in succession prior to the elution step in previous papers $[12,13]$, the poor recoveries of CQ and MQ (less than $10 \%$ ) were observed at the same conditions. It is possible that the sodium or potassium ions in the buffer replaced some of the CQ and MQ ions adsorbed onto the WCX cartridges. As a result, only methanol was used to wash the cartridges in this study.

The breakthrough volume of the WCX cartridge was examined by spiking CQ and MQ into Miyun Reservoir water of different volumes $(50,100$ and $150 \mathrm{~mL})$ to achieve a final concentration of $50 \mathrm{ng} \mathrm{L}^{-1}$. The recoveries were $98-107 \%$ for CQ and $97-110 \%$ for MQ when the water sample volume was $50-100 \mathrm{~mL}$. The recoveries, however, were $74 \%$ (CQ) and $81 \%$ (MQ) at a volume of $150 \mathrm{~mL}$. Therefore, the sample volume for extraction was determined to be $100 \mathrm{~mL}$.

\subsection{LC-MS method development}

For most previously published LC-MS or LC-MS/MS methods, a $\mathrm{C}_{8}, \mathrm{C}_{18}$ or silica-based reversed-phase column was usually applied with aqueous HFBA (15-20 mM) and methanol or acetonitrile as mobile phases for the analyses of CQ and MQ $[1,2,6,11,19,20]$. To remove the need for the use of the ion-pair reagent, HFBA, which can pollute the MS, the CAPCELL PAK CR 1:4 (SCX:C18=1:4) column containing strong cationic exchange resins and $\mathrm{C} 18$ was tested in this study. The results of optimization of the concentration of
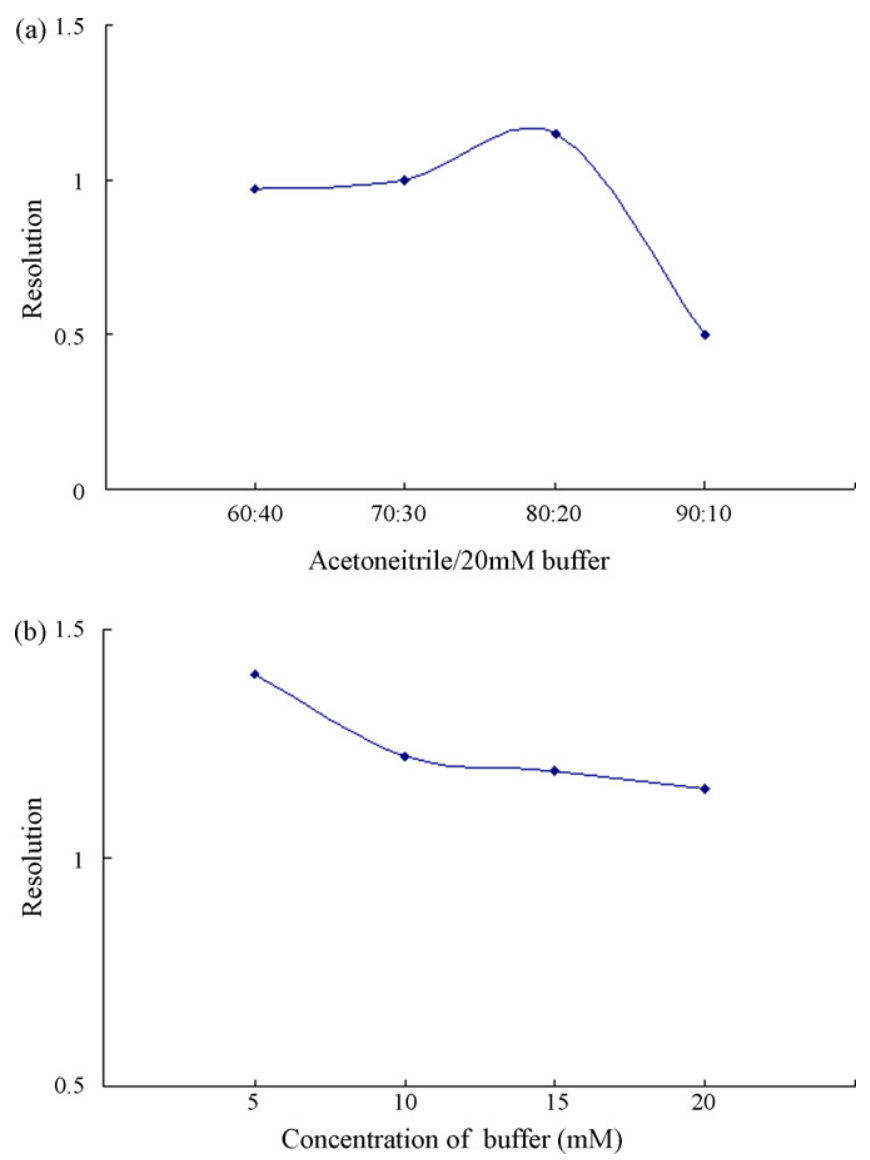

Fig. 1. Impact of the proportion of organic mobile phase (a) and concentration of buffer-salts (b) on separation efficiency $\left(50 \mu \mathrm{g} \mathrm{L}^{-1}\right)$ : (a) $20 \mathrm{mM}$ $\mathrm{CH}_{3} \mathrm{COONH}_{4}-\mathrm{CH}_{3} \mathrm{COOH}$ buffer was used; (b) the acetonitrile/buffer ratio was $80 / 20$ $(\mathrm{v} / \mathrm{v})$.

buffer-salts and the proportion of the organic mobile phase were optimized as shown in Fig. 1. Fig. 1 showed the impact of concentration of buffer-salts and the proportion of the organic mobile phase on separation efficiency. The highest separation efficiency was achieved at $5 \mathrm{mM} \mathrm{CH}_{3} \mathrm{COONH}_{4}-\mathrm{CH}_{3} \mathrm{COOH}$ and $80 \%$ acetonitrile. However, to meet the requirement of proper retention time, good resolution and the largest MS peak area, the separation condition was determined as $20 \mathrm{mM} \mathrm{CH}_{3} \mathrm{COONH}_{4}-\mathrm{CH}_{3} \mathrm{COOH}$ and $80 \%$ acetonitrile. Previous study solved the ion-pair reagents instrument fouling problem using HILIC column in LC-MS/MS method [18]. In comparison, a better retention was achieved under the condition of higher ratio of organic mobile phase (80\%) and lower concentration of buffer-salts $(20 \mathrm{mM})$ in this study.

Higher sensitivity was achieved in ESI (+) mode. Ionization and fragmentation conditions were optimized for CQ and MQ by continuous flow injection of pure standard solutions at $1 \mathrm{mg} \mathrm{L}^{-1}$ in acetonitrile-pure water $(80: 20, \mathrm{v} / \mathrm{v})$. LC-ESI-MS mass spectra for CQ and MQ were acquired by direct injection at difference cone voltages, as shown in Fig. 2. The molecular ions [Cat] ${ }^{+}$at $m / z 122$ and 114 were the most abundant peaks for $C Q$ and MQ respectively; thus, these were used as the quantification ions. The MS conditions were optimized for the individual plant growth regulators to achieve the highest relative abundance of [Cat $]^{+}$among all fragments (Table 1 ). At the cone voltage of $30 \mathrm{~V}, \mathrm{CQ}$ and $\mathrm{MQ}$ produced molecular ions [Cat] ${ }^{+}(\mathrm{m} / z 114$ and 122$)$ as a base peak, and qualifier ions of 115 and 124 . The presence of the $\mathrm{m} / z$ qualifier ion of 124 was due to the existence of the $\mathrm{Cl} 37$ isotope in a ratio of $3: 1$. The presence of the qualifier ion of 115 was due to the existence of the $\mathrm{C} 13$ isotope. At the cone voltage of $60 \mathrm{~V}$, the 

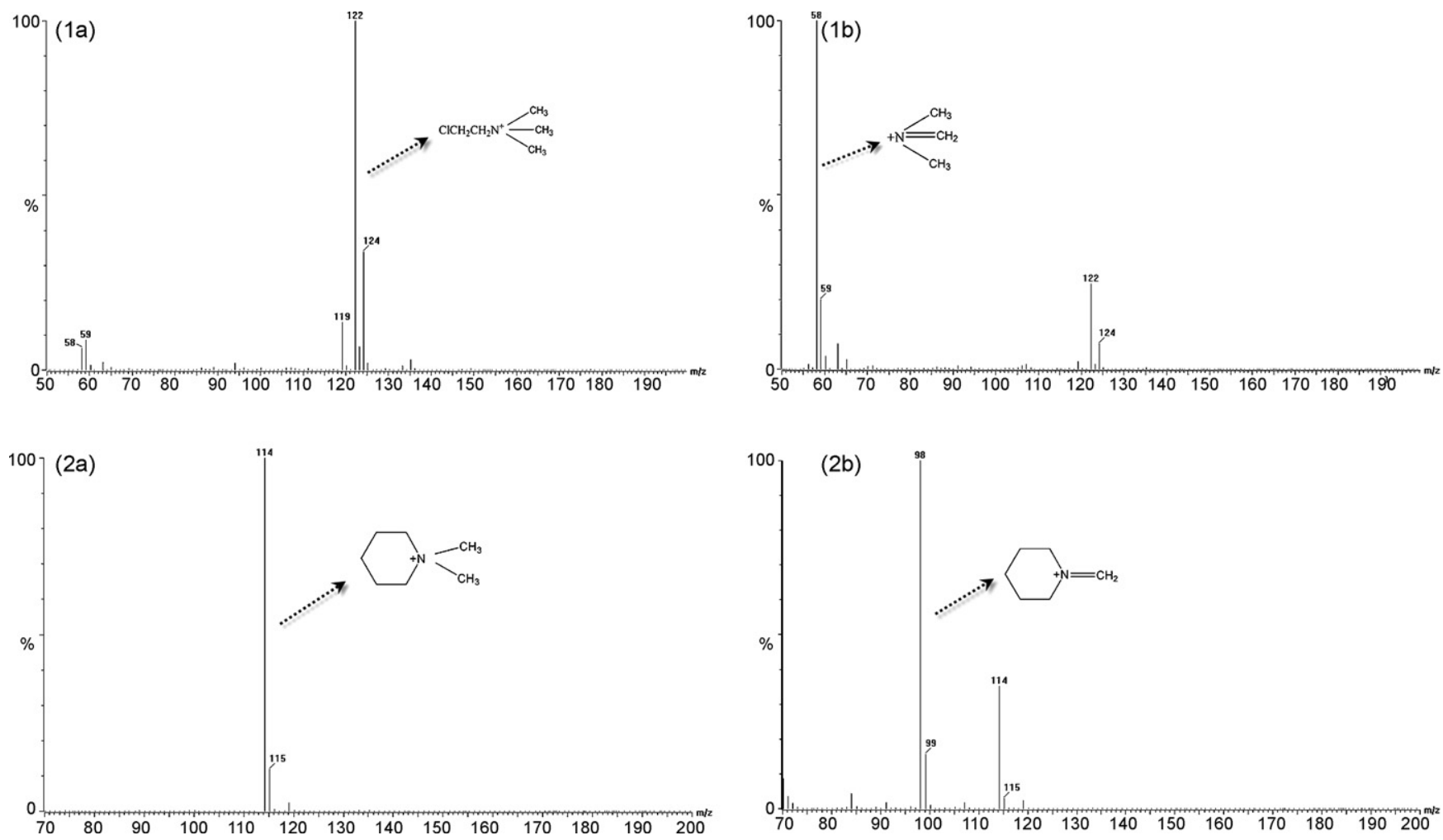

Fig. 2. LC-MS mass spectra for CQ (1a and $1 \mathrm{~b})$ and MQ (2a and $2 \mathrm{~b})$ in positive ion mode. Cone voltage: $30 \mathrm{~V}(1 \mathrm{a}$ and $2 \mathrm{a})$ and $60 \mathrm{~V}(1 \mathrm{~b}$ and $2 \mathrm{~b})$.

fragment ions of $58(\mathrm{~m} / \mathrm{z})\left(\left[\mathrm{Cat}-\mathrm{ClCH}_{2} \mathrm{CH}_{3}\right]^{+}\right)$and $98(\mathrm{~m} / \mathrm{z})([\mathrm{Cat}-$ $\left.\mathrm{CH}_{4}\right]^{+}$) were the base peaks in the mass spectra of CQ and MQ. Considering the probable trace level in the environment, all samples were subsequently analyzed with multi-channel mode with quantification performed at $30 \mathrm{~V}$ to ascertain the sensitivity and qualitative analysis performed at $60 \mathrm{~V}$ simultaneously. At the same time, the chromatographic retention time (with $2 \%$ ) was also used for the identification of the target compounds. The LC-MS total ion SIM chromatogram and the extracted-ion chromatogram of CQ and MQ in reference matrix is shown in Fig. 3, which indicates that the developed method was highly selective for the investigated plant growth regulators.

\subsection{Calibration curves and linearity}

The standard solutions of CQ and MQ in acetonitrile/DI water (80:20) were directly analyzed by LC-MS to optimize the instrumental conditions. In order to solve the problem of ESI-MS ion suppression during sample analysis, Miyun Reservoir source water samples were analyzed using SPE pre-concentration to establish
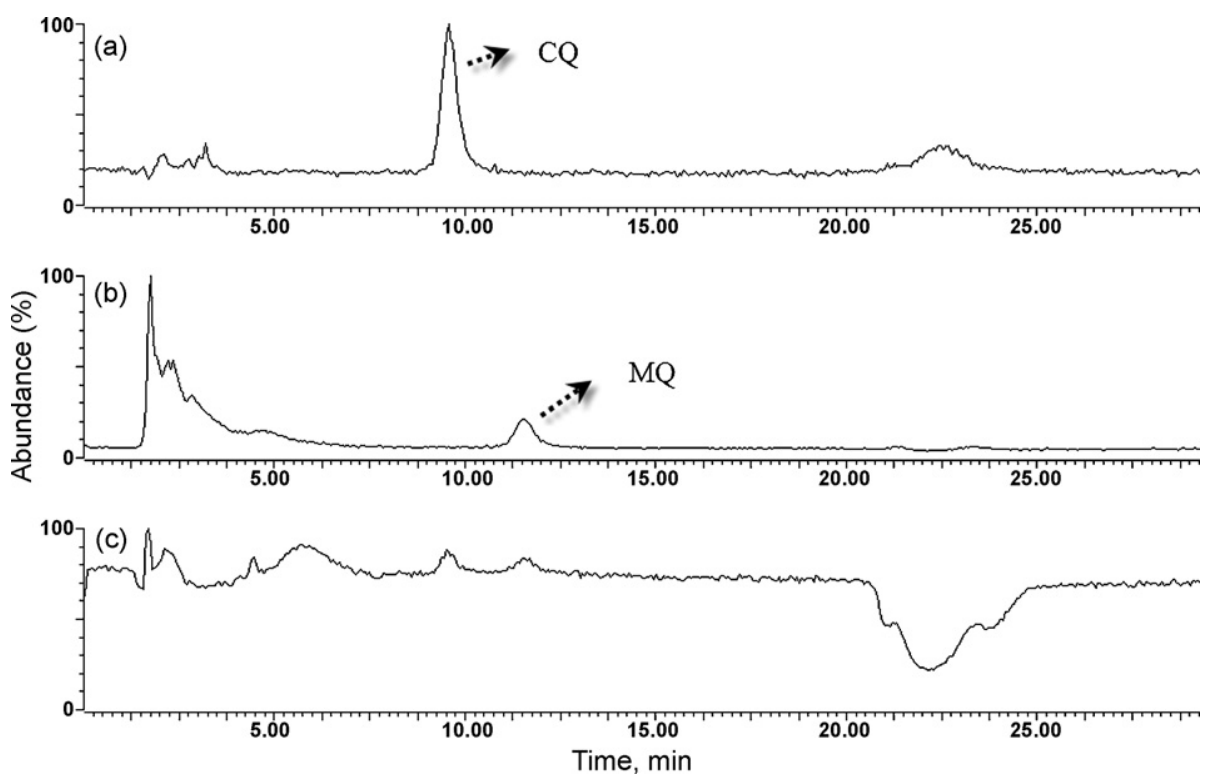

Fig. 3. The extracted ion chromatogram of $C Q(a)$ and $M Q(b)$ and total ion SIM chromatogram (c) recovered from a spiked in Miyun water sample ( $\left.0.1 \mu g \mathrm{~L}^{-1}\right)$. 
Table 2

Linear regression parameters of CQ and MQ in DI water and source water (each calibration curve includes five points).

\begin{tabular}{|c|c|c|c|c|c|}
\hline & & Linearity range $\left(\mu \mathrm{g} \mathrm{L}^{-1}\right)$ & Slope & $y$-Intercept & $r^{2}$ \\
\hline \multirow[t]{2}{*}{ Standard calibration curves (without SPE) } & CQ & $1-100$ & 9752 & 158 & 0.9996 \\
\hline & MQ & $1-100$ & 26,002 & -9751 & 0.9994 \\
\hline \multirow[t]{2}{*}{ Standard calibration curves (with SPE) } & $\mathrm{CQ}$ & $0.1-5$ & 603,568 & 71,918 & 0.9987 \\
\hline & MQ & $0.1-5$ & $2,146,049$ & 282,939 & 0.9989 \\
\hline
\end{tabular}

Table 3

Recovery and method detection limits for CQ and MQ in DI water and source water, respectively.

\begin{tabular}{|c|c|c|c|c|c|c|}
\hline \multirow[t]{2}{*}{ Name } & \multirow[t]{2}{*}{ Spike concentration $\left(\mu \mathrm{g} \mathrm{L}^{-1}\right)$} & \multicolumn{2}{|l|}{ DI } & \multicolumn{2}{|l|}{ SW } & \multirow[t]{2}{*}{$\operatorname{MDL}\left(\mathrm{ng} \mathrm{L}^{-1}\right)$} \\
\hline & & Recovery (\%) & RSD (\%) & Recovery (\%) & RSD (\%) & \\
\hline \multirow[t]{3}{*}{ CQ } & 0.1 & - & - & 96 & 4 & \multirow[t]{3}{*}{14} \\
\hline & 0.5 & 105 & 5 & 95 & 6 & \\
\hline & 1 & 97 & 4 & 105 & 2 & \\
\hline \multirow[t]{3}{*}{ MQ } & 0.1 & - & - & 118 & 4 & \multirow[t]{3}{*}{22} \\
\hline & 0.5 & 94 & 6 & 92 & 2 & \\
\hline & 1 & 114 & 4 & 117 & 1 & \\
\hline
\end{tabular}

matrix-matched standard calibrations for the quantification of CQ and MQ in source water samples. The matrix-matched calibration curves were established in the $0.1-5 \mu \mathrm{g} \mathrm{L}^{-1}$ range because the actual levels of the plant growth regulators are usually very low $[2,5]$. The linear regression data are summarized in Table 2 . The coefficients of determination $\left(r^{2}\right)$ were above 0.99 for all of the calibration curves, indicating that the matrix-matched calibration curves could be applied to quantify CQ and MQ in the source water.

\subsection{Recovery, precision and method detection limit}

According to the Environmental Water Quality Monitoring Assurance Handbook (China National Environmental Monitoring Center, CNEMC), the selected plant growth regulators were spiked at three concentration levels $\left(0.1,0.5\right.$, and $\left.1 \mu \mathrm{g} \mathrm{L}^{-1}\right)$ into DI water and the reference source water, and these samples were then subjected to the entire procedure developed here, including SPE and LC-MS analysis. As shown in Table 3, the recoveries of CQ and MQ ranged from $91 \%$ to $118 \%$ for both DI water and the reference source water. The method precision expressed by the relative standard deviation (RSD, \%) was determined to be $3 \%$ and $5 \%$ for CQ and MQ respectively ( $\left.n=7,0.1 \mu \mathrm{g} \mathrm{L}^{-1}\right)$.

In order to evaluate the performance of the LC-MS method, instrument detection limit (IDL) based on an S/N of 10:1 was calculated injecting $10 \mu \mathrm{L}$ of standard solutions at low concentrations. The IDL of our method is $0.1 \mu \mathrm{g} \mathrm{L}^{-1}$, lower than using HILIC column $\left(0.2 \mu \mathrm{g} \mathrm{L}^{-1}\right)$. The method detection limit (MDL) was calculated by analyzing seven spiked reference matrix samples at low concentration levels $\left(0.1 \mu \mathrm{gL}^{-1}\right)$ according to the EPA method [21]. The MDL values of the investigated plant growth regulators are shown in Table 3. The MDL obtained without using ion-pair reagents ( $14 \mathrm{ng} \mathrm{L}^{-1}$ for CQ and $22 \mathrm{ng} \mathrm{L}^{-1}$ for MQ) were comparable to those acquired using tandem MS ( $20 \mathrm{ng} \mathrm{L}^{-1}$ for CQ and $10 \mathrm{ng} \mathrm{L}^{-1}$ for MQ) and meet the EU's limit for water $\left(0.1 \mu \mathrm{gL}^{-1}\right)$ [1,2]. These findings demonstrate that although the developed method is based on single-MS, it is still applicable for detecting the target plant growth regulators in source waters.

\subsection{Application to environmental water samples}

Source water samples from six regions in China were collected and analyzed to evaluate the applicability of the developed method for the detection of CQ and MQ (Table 4 and Fig. 4). The identification of individual plant growth regulators in water samples was based on the chromatographic retention time (with $2 \%$ ) and the ratio (within $20 \%$ ) of the three selected characteristic ions accord-
Table 4

CQ and MQ concentrations detected in source water collected from six sites in China.

\begin{tabular}{lll}
\hline Source waters & $\mathrm{CQ}\left(\mu \mathrm{gL}^{-1}\right)$ & $\mathrm{MQ}\left(\mu \mathrm{g} \mathrm{L}^{-1}\right)$ \\
\hline Miyun & $\mathrm{ND}^{\mathrm{a}}$ & $\mathrm{ND}$ \\
Changjiang & 0.020 & $\mathrm{ND}$ \\
Yanghe & $\mathrm{ND}$ & $\mathrm{ND}$ \\
Huairou1 & $\mathrm{ND}$ & $\mathrm{ND}$ \\
Huairou2 & $\mathrm{ND}$ & $\mathrm{ND}$ \\
Weifang & 0.028 & $0.003^{\mathrm{b}}$ \\
\hline
\end{tabular}

a ND: not detected.

b 0.003 : lower than MDL.

ing to the standard samples. CQ was detected in two source waters at concentrations ranging from 20 to $28 \mathrm{ng} \mathrm{L}^{-1}$, while MQ was detected in only one of the two sites at below the MDL. Weifang, which is an area in which a high volume of vegetables are produced, was the only site where both CQ and MQ were detected. Although the concentrations detected in these samples are well below the maximum contaminated levels legislated by the European Union, further monitoring of these plant regulators is required since different vegetables will be grown in different seasons, which may result in variations in the concentrations in the source water.

Vidal et al. investigated the contamination levels of CQ and MQ in 40 environmental water samples collected from Andalusia (South Spain) using LC-MS-MS and found that the concentrations were below the detection limits $\left(0.02 \mu \mathrm{g} \mathrm{L}^{-1}\right)$ [11]. Additionally, Henriksen et al. investigated the CQ concentrations in 66 groundwater samples collected from Copenhagen and detected no CQ [22].

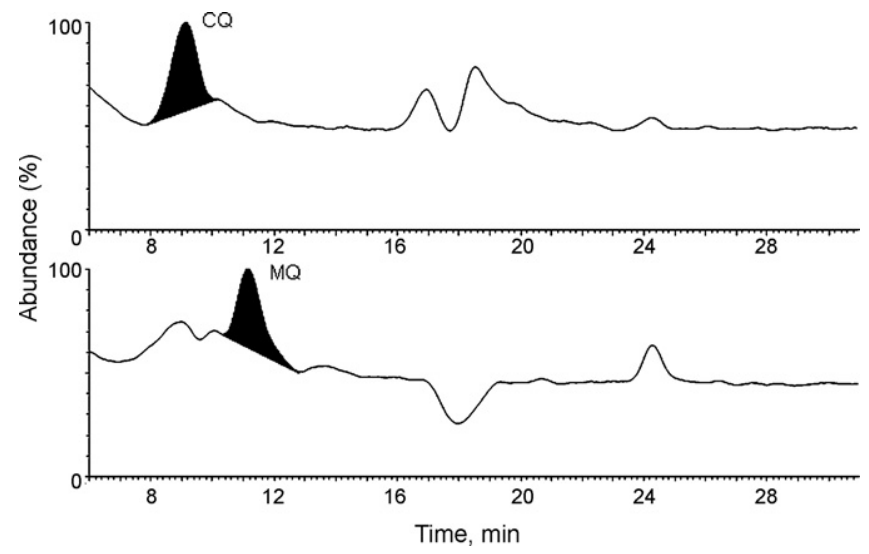

Fig. 4. Chromatograms of $C Q$ and $M Q$ in Weifang source water. 
Therefore, this is the first report of the occurrence of CQ and MQ in groundwater.

\section{Conclusion}

A method for analysis of chlormequat (CQ) and mepiquat (MQ) in source water samples using off-line solid-phase extraction (SPE) and liquid chromatography-mass spectrometry (LC-MS) was developed. The adoption of the CAPCELL PAK CR 1:4 (SCX:C18=1:4) column successfully solved the problem of mass spectrometry contamination caused by the use of ion-pair reagents such as heptafluorobutyric acid (HFBA), and the adoption of WCX cartridge solved the pre-concentration problem of CQ and MQ in the source water. The MDL obtained using single-MS can meet the EU's limit for water $\left(0.1 \mu \mathrm{gL}^{-1}\right)$. Investigation of source water from several regions revealed that some source waters have been contaminated by $\mathrm{CQ}$ and MQ; therefore further study should be conducted to determine the extent of such contamination.

\section{Acknowledgements}

This work was financially supported by the National Basic Research Program of China [2006CB403306] and the Central Publicinterest Scientific Institution Basal Research Foundation Program of China [0032007228].

\section{References}

[1] R. Castro, E. Moyano, M.T. Galceran, J. Chromatogr. A 869 (2000) 441-449.

[2] R. Castro, E. Moyano, M.T. Galceran, J. Chromatogr. A 914 (2001) 111-121.

[3] O. Núñez, E. Moyano, M.T. Galceran, J. Chromatogr. A 974 (2002) 243-255.

[4] R. Castro, E. Moyano, M.T. Galceran, Chromatographia 53 (2001) 273-278.

[5] Y.Zhao, K. Lazou, M. Schelfaut, L. De Reu, P. Sandra, Chromatographia 51 (2000) 531-535.

[6] M.A. Aramendía, V. Borau, F. Lafont, A. Marinas, J.M. Marinas, J.M. Moreno, J.M. Porras, F.J. Urbano, Food Chem. 97 (2006) 181-188.

[7] Available from: http://www.scorecard.org/health-effects/chemicals-2.tcl? short_hazard_name=endo\&all_p=t.

[8] O. Núñez, E. Moyano, M.T. Galceran, Anal. Chim. Acta 525 (2004) 183-190.

[9] M.E. Poulsen, H.B. Christensen, M.T. Sorensen, H. Leffers, J.H. Andersen, Anal. Bioanal. Chem. 389 (2007) 1799-1804.

[10] L. Alder, J.R. Startin, J. AOAC Int. 88 (6) (2005) 1762-1776.

[11] J.L.M. Vidal, A.B. Vega, F.J.S. López, A.G. Frenich, J. Chromatogr. A 1050 (2004) $179-184$

[12] Y. Picó, M. Fernández, M.J. Ruiz, G. Font, J. Biochem. Biophys. Methods 70 (2007) $117-131$

[13] M.S. Young, U.D. Neue, K.M. Jenkins, Waters AGRO \#48 (2004).

[14] M.S. Young, K.M. Jenkins, The Application Notebook of Waters Co., September 2004, pp. 2-3.

[15] S. Gao, S. Bhoopathy, Z.P. Zhang, D.S. Wright, R. Jenkins, H.T. Karnes, J. Pharm. Biomed. Anal. 40 (2006) 679-688.

[16] K.L. Rundlett, D.W. Armstrong, Anal. Chem. 68 (1996) 3493-3497.

[17] B.H. Forngren, J. Samskog, S.Å. Gustavsson, N. Tyrefors, K.E. Markides, B. Långstrom, J. Chromatogr. A 854 (1999) 155-162.

[18] X. Esparza, E. Moyano, M.T. Galceran, J. Chromatogr. A 1216 (2009) 4402-4406.

[19] J. Hau, S. Riediker, N. Varga, R.H. Stadler, J. Chromatogr. A 878 (2000) 77-86.

[20] S. Riediker, H.h. Obrist, N. Varga, R.H. Stadler, J. Chromatogr. A 966(2002)15-23.

[21] L.J. Liu, X.Z. Zhang, K.M. Lu, Water Purif. Technol. 22 (1) (2003) 37-39.

[22] T. Henriksen, R.K. Juhler, G. Brandt, J. Kjær, J. Chromatogr. A 1216 (2009) 2504-2510. 